\title{
Comparison of Experimental Methods to Assess the Competitive Ability of Weed Species
}

\author{
Leandro Galon ${ }^{1}$, Germani Concenço ${ }^{2}$, Gismael Francisco Perin'1, \\ Alexandre Ferreira da Silva ${ }^{3}$, Cesar Tiago Forte', Felipe de Adelio David', \\ Lauri Lourenço Radüz¹, André Luiz Radunz ${ }^{1}$, André Andres ${ }^{4}$, Siumar Pedro Tironi5, \\ Samara Emerim Concenço ${ }^{6}$
}

\footnotetext{
${ }^{1}$ Plant Science Department, Federal University of the Southern Border, Erechim, Brazil

${ }^{2}$ Weed Science, Embrapa Western Agriculture, Dourados, Brazil

${ }^{3}$ Embrapa Maize and Sorghum, Sete Lagoas, Brazil

${ }^{4}$ Weed Science, Embrapa Temperate Agriculture, Pelotas, Brazil

${ }^{5}$ Plant Science Department, Federal University of the Southern Border, Chapecó, Brazil

${ }^{6}$ Federal Institute of Santa Catarina at Santa Rosa do Su-SC, Santa Rosa do Sul, Brazil

Email: leandro.galon@uffs.edu.br
}

Received 29 June 2015; accepted 26 August 2015; published 31 August 2015

Copyright (C) 2015 by authors and Scientific Research Publishing Inc.

This work is licensed under the Creative Commons Attribution International License (CC BY).

http://creativecommons.org/licenses/by/4.0/

(c) (i) Open Access

\begin{abstract}
Competition between crops and weeds interfere on growth and development with harm to one or both, in different ways. To quantify these differences in competition, additive and replacement series study methods are most often used, each with different characteristics and goals. Therefore, we aimed with this work to study inter-specific competition between plants of soybean and corn against the weeds Bidens pilosa (beggartick) and Digitaria insularis (sourgrass), by two experimental methods of study: additive and replacement series (substitutive) experiments. Initial tests were performed prior to the installation of replacement series experiments to describe the intra-specific competition features for all species. For additive experiments these are unnecessary. To compare the methods of study, there were two sets of trials (an additive and a substitutive) installed under greenhouse, during the growing season 2013/14. Variables analyzed were leaf area and dry weight of shoots of crops and weeds, at 50 days after emergence. The results were analyzed according to the methods used, these being compared. It was found that the additive method supplied results most prone to be applied in the field, while the replacement series (substitutive) method was more appropriate for studies that aimed to provide detailed scientific information regarding the proportions of plants and coefficients describing the behavior of the species community.
\end{abstract}




\section{Keywords}

\section{Interference, Zea mays, Glycine max, Weeds}

\section{Introduction}

In the period between sowing and emergence, the future crop plant depends almost exclusively on resources stored in the seed. After the seedling emerges to the soil surface, the resources necessary for its growth and development are captured from the environment. What determines whether a plant will succeed in completing its cycle is mainly its ability to extract and use environmental resources such as light, water and nutrients. Successful plants will produce abundant offspring while the less able plants senesces leaving few or no descendants.

Plants typically do not occur alone in their habitat having to live well with other plants of the same species, as with individuals of other species. When resources become scarce in the environment, the process of interference starts. Interference is defined as the effect of one plant on the environment also occupied by its neighbors, being positive, negative or neutral, and arising when resources become limited, when one of the species produce allelopathic compounds, or when predation occurs. The types of interference, due to the proximity of two theoretical subjects, can be classified as [1]: neutralism, competition, mutualism, proto-cooperation, commensalism, amensalism, parasitism, predation and herbivory.

Among these, competition, parasitism and amensalism result in negative interference. For the weed science, competition (for water, light and nutrients) can occur at any time from the beginning of the seed soaking for germination on, although it is more significant in areas with more developed individuals, or in areas with excessive number of individuals [2]. Competition is defined as the dispute established between individuals when a plant is in a group of other plants, or when it is surrounded by its descendants [2].

If individuals of the same species compete for a particular resource, the competition is called intra-specific. If competition occurs between individuals of different species, it is called inter-specific. The intra-specific competition is more intense than inter-specific [3] due to the complete niche overlap to be explored when two similar plants are confronted. Plants of the same species are more likely to germinate at the same time, have the same life cycle and change phase in the development at the same time; therefore, they are always competing for the same resources.

The competition may occur for resources or conditions. Conditions are environmental factors that are not directly consumable, but they influence the use of resources, i.e., they affect the ability of the individual to use the resource. As an example, $\mathrm{pH}$ can change the availability of nutrients in soil, the average temperature of the air can limit photosynthetic activity and air humidity and soil moisture can influence-together with light, the stomatal opening and closure cycles. Resources are factors directly consumables such as water, $\mathrm{CO}_{2}$, light and nutrients, and usually the response of plants to these resources follows a standard curve: the growth is limited under low levels of resource, increasing to the point of saturation, at which time the feature can become toxic and the growth rate decays again.

There are methods of study that contribute to the management strategy of weeds. These should consider the population, the spatial arrangement and the proportion of plants in the associations [4]. To assess the intensity of competition between crop and weeds, two study methods are more often used: the "additive" and the "replacement series" (also called "substitutive") methods. The additive method comprises the increase in the number of weeds, keeping constant the number of crop plants, and the analysis of the variables is given by regression. The substitutive method, in contrast, provides that the final population is constant being a given plant substituted by other of the opposite species when it disappears. The analysis takes place by diagrams of relative and total yields. For the substitute method, pre-testings are necessary for all species involved. With the pre-test, the objective is to determine the minimum density of each species (plants $\mathrm{m}^{-2}$ ) from which the mass per unit area increase is negligible even with an increase in planting density [5].

Each study method is different in its essence, where the additive experiments aim to investigate the impact on increasing the density of the weed compared to crop plants when the latter is not sown in density which gives the maximum competitive potential, which is similar to the observed in commercial crop fields. Therefore, it is proposed that results from additive experiments tend to be more practical. The replacement series, in contrast, 
aim to compare theoretical situations not observed in the field, where both crop and weed are planted in densities which confer them maximum competitive ability. We hypothesize that this method may be more suitable for studies of competition for morpho-physiological and environmental resources when a complete understanding of the competitive process is required.

Given the above, this study aims to evaluate the inter-specific competition between plants of soybean and corn competing with the weeds Bidens pilosa (beggartick) and Digitaria insularis (sourgrass) by using and comparing two different study methods: additive and replacement series (substitutive) experiments.

\section{Materials and Methods}

The soil used in the pre-tests (substitutive method) and final tests (additive and substitute methods) was corrected according to the results of the chemical analysis, being added per ton of soil $166 \mathrm{~g}$ of ammonium sulfate, $723 \mathrm{~g}$ of triple super phosphate and $115 \mathrm{~g}$ of potassium chloride. Twenty days after plant emergence fertilizer was also performed as topdressing by diluting $1.24 \mathrm{~g}$ of potassium chloride and $2.23 \mathrm{~g}$ of ammonium sulfate in $500 \mathrm{ml}$ of water, which was applied per pot.

\subsection{Additive Experiments}

Four experiments were conducted by the additive method aiming to evaluate the competition of corn and soybeans in the presence of the weeds beggartick and sourgrass, being installed in completely randomized design with four replications. Experimental units were kept equidistant, so that the surface area available for the development of the plants corresponded to the area of the experimental unit, this being composed of plastic pots with a capacity of 10 liters of soil.

In the center of the plastic pot (experimental unit) were sown three seeds of the crop (soybean for experiments 1 and 2, and corn for experiments 3 and 4), and in the periphery the weeds were sown (beggartick in experiments 1 and 3, and sourgrass in experiments 2 and 4). Ten days after emergence of the crop and weeds, thinning was carried out being kept only one plant of the crop in the center of each experimental unit, and the number of weeds in the periphery according to each proposed treatment (Table 1) for each experiment. Thinning was repeated weekly three times in order to eliminate new emergence flows of weeds.

Fifty days after emergence, all plants of the experimental unit were cut close to the ground, being separated by type (crop or weed), packed in paper bags and placed into an oven with forced air circulation at $65^{\circ} \mathrm{C}$ to achieve constant weight for subsequent measurement of total dry mass. The data were submitted to the verification of normality by Shapiro-Wilk and homogeneity of variances by Bartlett, being transformed when necessary, and then subjected to analysis of variance by the $\mathrm{F}$ test at $5 \%$ probability. When treatment effect was significant, data were explored by nonlinear regression analysis being the regression fit judged by the mean square of the regression analysis, and by the adjustment coefficient $\left(\mathrm{R}^{2}\right)$. All analyzes were performed into the statistical environment "R" [6] and graphs were drawn into SigmaPlot version 12.5 .

\subsection{Substitutive Experiments-Pre Tests}

For the studies by the substitute method, pre-tests were installed, with each species studied planted alone at densities from 1 to 1500 plants $\mathrm{m}^{-2}$. The aim of the pre-test was to determine the minimum density of that species

Table 1. Crops and weeds, with respective plant densities, studied in each one of the four additive experiments installed. Embrapa Western Agriculture, Dourados-MS, Brazil, 2015.

\begin{tabular}{|c|c|c|c|c|c|c|}
\hline \multirow{2}{*}{ Experiment } & \multirow{2}{*}{ Crop } & \multirow{2}{*}{ Weed } & \multicolumn{2}{|c|}{ Crop Plants $^{A}$} & \multicolumn{2}{|c|}{ Weed Plants $^{B}$} \\
\hline & & & Vase $^{-1}$ & $\mathbf{m}^{-2}$ & Vase $^{-1}$ & $\mathbf{m}^{-2}$ \\
\hline 1 & Soybean & Beggartick & 1 & 14 & $0-1-2-3-4$ & $0-16-32-48-64$ \\
\hline 2 & Soybean & Sourgrass & 1 & 14 & $0-1-2-3-4$ & $0-16-32-48-64$ \\
\hline 3 & Corn & Beggartick & 1 & 14 & $0-1-2-3-4$ & $0-16-32-48-64$ \\
\hline 4 & Corn & Sourgrass & 1 & 14 & $0-1-2-3-4$ & $0-16-32-48-64$ \\
\hline
\end{tabular}

${ }^{\mathbf{A}}=$ for all treatments $(\mathrm{T} 1-\mathrm{T} 5)$, a single crop plant (corresponding to 14 plants $\cdot \mathrm{m}^{-2}$ ) was kept at the center of the experimental unit; ${ }^{\mathbf{B}}=$ number of weed plants kept at the periphery of the experimental unit, respectively for T1, T2, T3, T4 and T5. 
from which the dry mass per area increment was negligible even with the increase in plant density [5]. The results of the pre-tests were evaluated 50 days after emergence of the crop (beginning of the reproductive stage), showing mass stabilization from 16, 40, 60 and 20 plants per pot (224, 560, 840 and 280 plants $\left.\cdot \mathrm{m}^{-2}\right)$ on, respectively for corn, soybean, sourgrass and beggartick (Figure 1). Plants were sprinkler irrigated as needed, being soil kept moist near field capacity.

\subsection{Substitutive Experiments}

Four experiments were conducted by the substitutive (replacement series) method, under completely randomized design with four replications. The experimental units were kept equidistant, so that the surface area available for the development of the plants corresponded to the area of the experimental unit composed of plastic pots with a volume of 10 liters of soil. Seeds of beggartick or sourgrass were randomly allocated in the vases, according to the treatments, being enough to establish at least 20 and 60 plants per vase, respectively. Thereafter, soybean or corn were planted, according to the treatments (Table 2), aiming to establish at least 40 and 16 plants per pot, respectively (Table 2), according to the results of the pre-tests (Figure 1).

Ten days after emergence, thinning was accomplished being kept the number of crop plants and weeds per pot according to the treatments (Table 2). Thinning was repeated every seven days for three weeks in order to eliminate new seedlings emerged.

Fifty days after emergence, all plants of each experimental unit were cut close to the ground, separated according to the species (crop or weed), packed in paper bags and placed into an oven with forced air circulation at $65^{\circ} \mathrm{C}$, until constant mass for subsequent measurement of total dry mass. The graphical analysis of variation, or relative productivity [5] was obtained, which involved the construction of relative (PR) and total (PRT) productivities
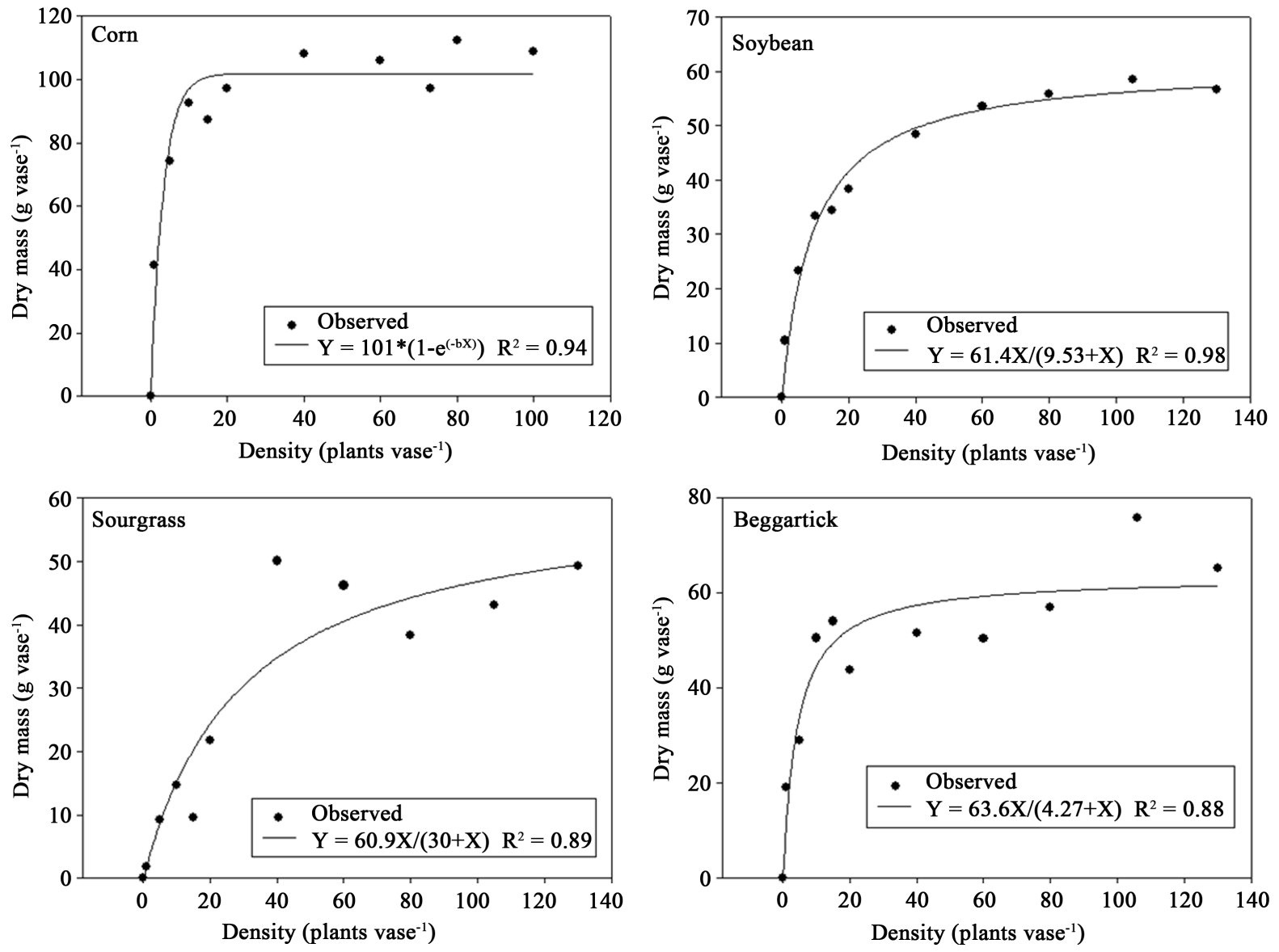

Figure 1. Plant densities in the pre-tests which equaled to $100 \%$ of the competitive potential for corn, soybean, sourgrass and beggartick, respectively with 16, 40, 60 and 20 plants per vase. Embrapa Western Agriculture, Dourados-MS, Brazil, 2012. 
Table 2. Crops and weeds, with respective plant densities, studied in each one of the four substitutive (replacement series) experiments installed. Embrapa Western Agriculture, Dourados-MS, Brazil, 2015.

\begin{tabular}{ccccccc}
\hline \multirow{2}{*}{ Experiment } & \multirow{2}{*}{ Crop } & Weed & \multicolumn{2}{c}{ Crop Plants $^{\mathbf{A}}$} & \multicolumn{2}{c}{ Weed Plants $^{\mathbf{B}}$} \\
\cline { 4 - 7 } & & & Vase $^{-1}$ & $\mathbf{m}^{-2}$ & Vase $^{-\mathbf{1}}$ & $\mathbf{m}^{-2}$ \\
\hline 5 & Soybean & Beggartick & $0-10-20-30-40$ & $0-140-280-420-560$ & $20-15-10-5-0$ & $280-210-140-70-0$ \\
6 & Soybean & Sourgrass & $0-10-20-30-40$ & $0-140-280-420-560$ & $60-45-30-15-0$ & $840-630-420-210-0$ \\
7 & Corn & Beggartick & $0-4-8-12-16$ & $0-56-112-168-224$ & $20-15-10-5-0$ & $280-210-140-70-0$ \\
8 & Corn & Sourgrass & $0-4-8-12-16$ & $0-56-112-168-224$ & $60-45-60-15-0$ & $840-630-420-210-0$ \\
\hline
\end{tabular}

$\mathbf{A}=$ number of crop plants randomly present in the experimental unit, respectively for T1, T2, T3, T4 and T5; B = number of weed plants randomly present in the experimental unit, respectively for T1, T2, T3, T4 and T5.

The expected values are indicated in the graph by dotted lines and the values observed by solid lines. When PR is a straight line (observed = expected), there is equivalence in the competitive ability of both species. PR line below the expected indicates harm to the growth of the species, and PR line above the expected indicates benefit to the growth of the species [5]. When PRT $=100 \%$, there is competition for the same resources; PRT $>100 \%$ indicates that the competition is avoided, and PRT $<100 \%$ indicates mutual damage for growth [5]. Differences between treatments for estimated and observed values of PR and PRT were compared by their standard errors of the means, being considered as distinct when the estimated values were not in the range of the standard error for the observed averages [7].

The relative competitiveness index (CR), relative clustering coefficient (K) and aggressiveness (A) were obtained, as well as their standard errors. CR is the comparative growth of a species relative to the other under competition; $\mathrm{K}$ indicates the relative dominance of one species over another; A determines which species is more aggressive in the competition. Species 1 is more competitive than species 2 when $\mathrm{CR}_{1}>1, \mathrm{~K}_{1}>\mathrm{K}_{2}$ and $\mathrm{A}>$ 0 , and vice-versa [8]. To calculate these indices the 50:50 proportions of species were used for the following equations: $\mathrm{CR}_{1}=\mathrm{PR}_{1} / \mathrm{PR}_{2} ; \mathrm{CR}_{2}=\mathrm{PR}_{2} / \mathrm{PR}_{1} ; \mathrm{K}_{1}=\mathrm{PR}_{1} /\left(100-\mathrm{PR}_{1}\right) ; \mathrm{K}_{2}=\mathrm{PR}_{2} /\left(100-\mathrm{PR}_{2}\right) ; \mathrm{A}_{1}=\mathrm{PR}_{1}-\mathrm{PR}_{2}$ and $\mathrm{A}_{2}=\mathrm{PR}_{2}-\mathrm{PR}_{1}$ as suggested by other studies. The significance of CR and A were measured by the one sample T-test, being considered significant when differed $(p \leq 0.05)$ from 1 and 0 , respectively. Difference between $\mathrm{K}_{1}$ and $\mathrm{K}_{2}$ were compared by the two sample T-test with Welch criteria, being significant when $p \leq 0.05$. All graphics and coefficients were obtained into the statistical environment " $R$ " [6].

\section{Results and Discussion}

\subsection{Additive Experiments}

Dry mass accumulation for soybean when competing with beggartick shows that when both co-emerge, there is reduction in dry mass of crop plants of the order of 30\%. This reduction in dry mass of plants may, especially under unfavorable conditions, reflect on crop productivity. Drastic reduction was observed when a single soybean plant competed with two or more plants of beggarticks (Figure 2); considering the densities of normal soybean plants in the field (400,000 plants $\cdot \mathrm{ha}^{-1}$ ), it can be proposed that plant densities of beggartick equal to or greater than 20 plants $\cdot \mathrm{m}^{-2}$, concomitantly emerged with the crop, can cause severe damage to yields.

Beggartick caused damage to the development and dry mass accumulation of corn, linearly to the increase in density, and for each additional beggartick plant per square meter emerged concomitantly to the crop, each corn plant reduced accumulation of $2.63 \mathrm{~g}$ of dry mass (Figure 2). This level of infestation is commonly observed in non-GM soybean crops because of the difficulty in controlling beggartick, especially the resistant biotype to ALS inhibitors that occurs in much of the state of Mato Grosso do Sul.

Sourgrass, on the other hand, caused virtually no damage to the development of soybean when emergence is concomitant, since there are no limiting factors for the production system. Crops have been improved and selected to respond to higher levels of factors such as the availability of nutrients and water, and its lack causes more damage to crops compared to weeds [8] (Figure 2). Another study did not find any correlation between the dry mass of different soybean genotypes and their productivity, although this relationship is usually significant when considering the same plant genotype, being more accurate when dry mass is assessed closer to harvest [9]. 

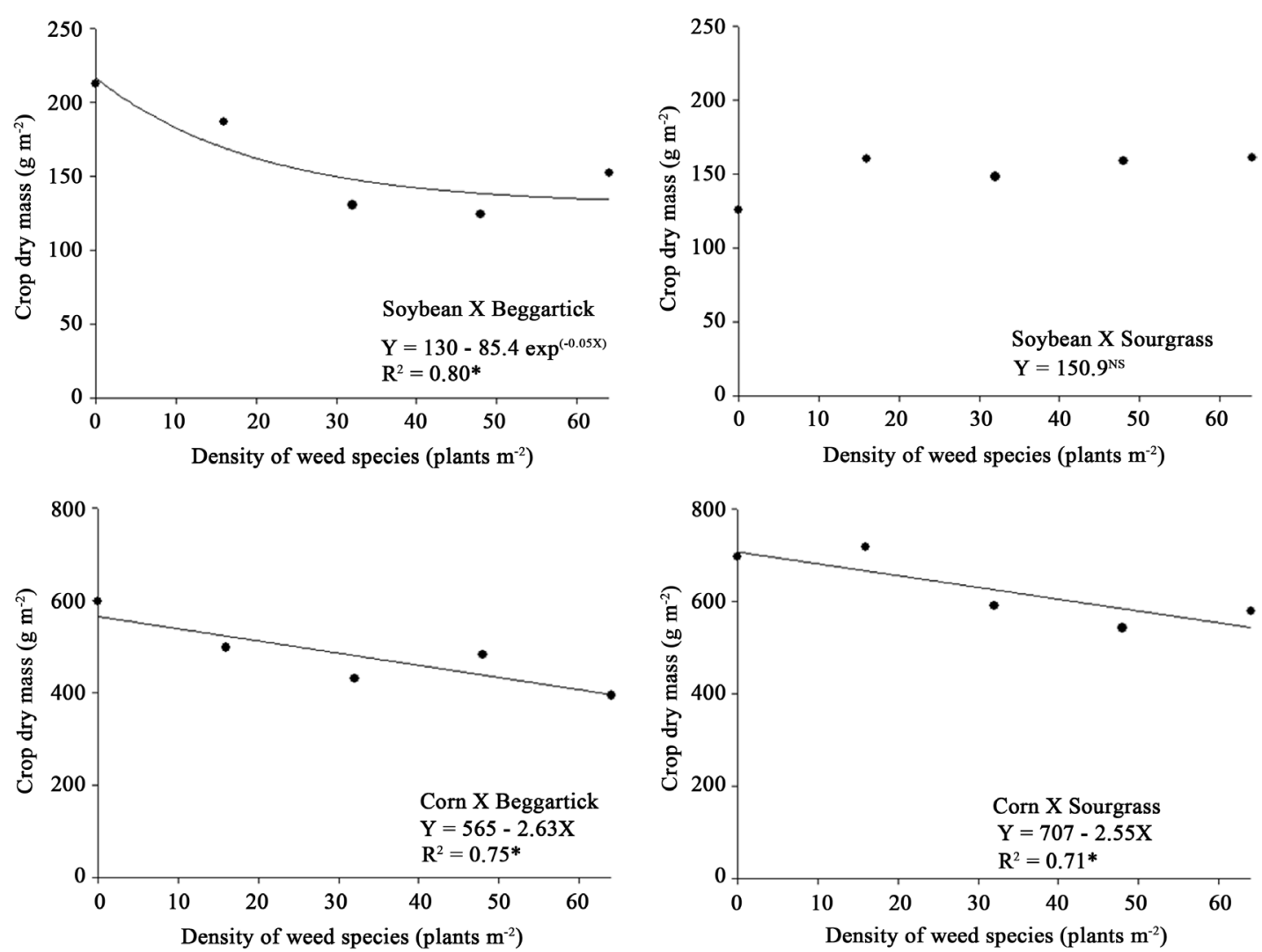

Figure 2. Dry mass of the single crop plant (soybean or corn) at the center of the experimental unit (corresponding to 14 plants $\cdot \mathrm{m}^{-2}$ ) as a function of competition level against beggartick or sourgrass, in densities from 0 to 64 plants $\cdot \mathrm{m}^{-2}$. Embrapa Western Agriculture, Dourados-MS, Brazil, 2015.

\subsection{Substitutive Experiments}

\subsubsection{Soybean versus Beggartick}

Beggartick was affected by soybean in all living ratios (Figure 3) in substitutive experiments. The larger inhibitions of this weed were observed when $75 \%$ of beggartick plants competed with $25 \%$ of soybean (in terms of competitive potential), at which point the observed productivity was farthest from the expected.

In soybean, beggartick in low densities causes significant losses, but if it provided the fastest development to crop, this weed is properly suppressed by soybean complementarily to chemical control. The Genus Bidens infests several crops, being highlighted Bidens pilosa with worldwide occurrence, being also very aggressive and efficient in the extraction of water from soil [9].

Soybean, regardless of its proportion, accumulated dry mass volumes close to the expected (Figure 3); this illustrates its potential to suppress beggartick under field conditions, although with some harm to its own development. With proportion of $75 \%: 25 \%$ soybean/beggartick, as example, dry mass of crop was $61 \%$ of the total obtained in the community, compared to the expected ratio of $75 \%$ (Figure 3). In the same situation, the dry weight of the weed, which should represent $25 \%$ of the system, represented something around $5 \%$.

The ecological system (soybean + beggartick) was hampered by competition, and the total productivity of the system (PRT), which should be $100 \%$, has always been lower than expected, with $55 \%$ reduction at proportion 75:25 beggartick/soybean (Figure 3).

In summary, there were losses in the system when soybean competed with beggartick, being the crop superior in competitive ability although it suffered due to the need for energy to be applied in competition against the weed instead of growth. In fact, the relative competitiveness (CR) and aggressiveness (A) coefficients indicated that soybean is more competitive than beggartick, which was also reflected by the clustering coefficient (K) (Table 3). However, when considering the density of the crop and the weed under field conditions, one should see the need for associating weed control methods to optimize soybean suppression on this weed. 


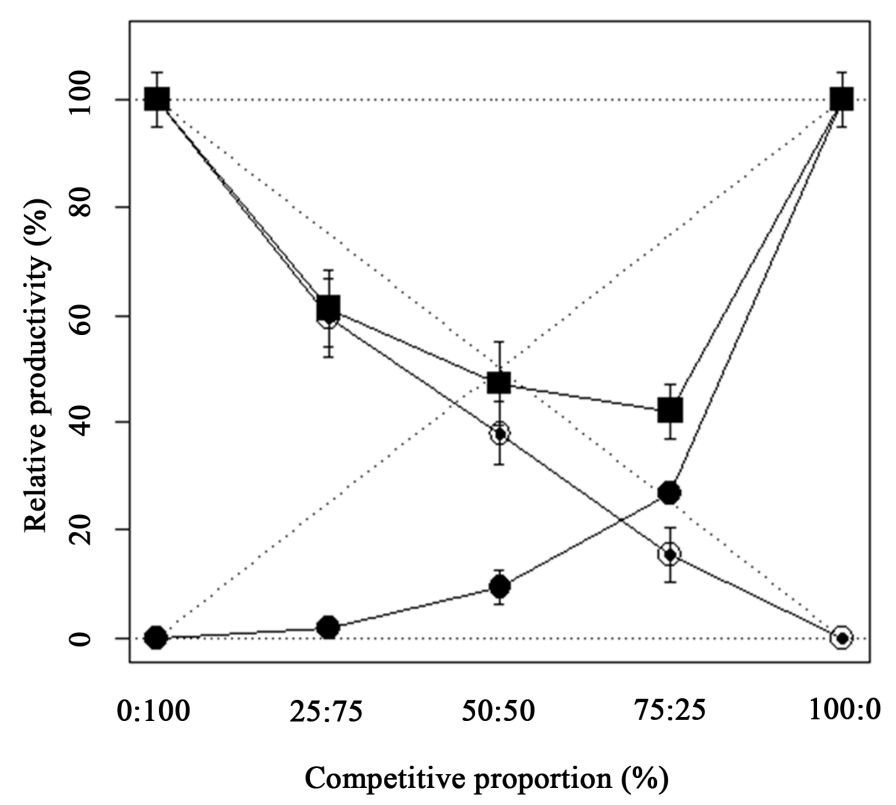

Figure 3. Relative productivity (PR) for shoot dry mass of beggartick $(\bullet)$ and soybean $(\odot)$, and total relative productivity (PRT) of the community (घ) as a function of plant proportion (beggartick: soybean). Dashed lines represent the expected values, in absence of competition, and solid lines the observed values when both species competed in different plant proportions. The standard error bars for treatment replications are presented for each treatment mean. Embrapa Western Agriculture, Dourados-MS, Brazil, 2015.

Table 3. Relative competitiveness (CR), clustering (K) and aggressiveness (A) coefficients for plants of soybean and beggartick under competition. Embrapa Western Agriculture, Dourados-MS, Brazil, 2015.

\begin{tabular}{|c|c|c|c|c|c|c|}
\hline \multirow{2}{*}{$\begin{array}{l}\text { Species } \\
\text { Soybean }\end{array}$} & \multicolumn{2}{|c|}{ CR } & \multicolumn{2}{|c|}{$\mathbf{K}$} & \multicolumn{2}{|c|}{ A } \\
\hline & $4.046^{*}$ & \pm 0.252 & $0.465 \mathrm{a}$ & \pm 0.029 & $0.251^{*}$ & \pm 0.029 \\
\hline Beggartick & $0.262^{*}$ & \pm 0.373 & $0.072 \mathrm{~b}$ & \pm 0.015 & & \\
\hline
\end{tabular}

CR and A: T-test, being considered significant when differed $(p \leq 0.05)$ from 1 and 0 , respectively. Difference between $\mathbf{K}_{\mathbf{S}}$ and $\mathbf{K}_{\mathbf{B}}$ were compared by the T-test with Welch criteria, being significant when $p \leq 0.05$.

\subsubsection{Soybean versus Sourgrass}

Similarly to what happened with beggartick, sourgrass caused reduction in mass accumulation of soybean in all densities of establishment, with linear losses of about 6\% compared to the expected values (Figure 4). The development of sourgrass was strongly suppressed by soybean, achieving reduction in dry mass of about $42 \%$ when crop and weed were equal in competitive ability (50:50). The system (PRT) also recorded losses by competition; the reduction reached $50 \%$ at $50: 50$, with $6 \%$ of dry mass reduction attributed to soybean and $42 \%$ to sourgrass. Although for density 75:25 sourgrass shortly reacted, this was not enough to raise mass accumulation to values close to those expected (Figure 4).

Competitiveness coefficients (CR) and aggressiveness (A) indicated that soybean was more competitive than sourgrass, since $\mathrm{CR}_{\text {soybean }}>1$; and $\mathrm{A}_{\text {soybean }}>0$; the clustering coefficient $(\mathrm{K})$ was also significantly higher $(p=$ 0.091) for crop (Table 4).

\subsubsection{Corn versus Beggartick}

Corn is usually considered a species highly competitive against weeds due to its architecture and size; as an improved plant, however, it has been adapted to target the largest possible part of assimilates to the production of grains at the expense of dry mass accumulation. Weeds, on the other hand, have been selected in the environment for its ability to compete and survive in harsh conditions. 


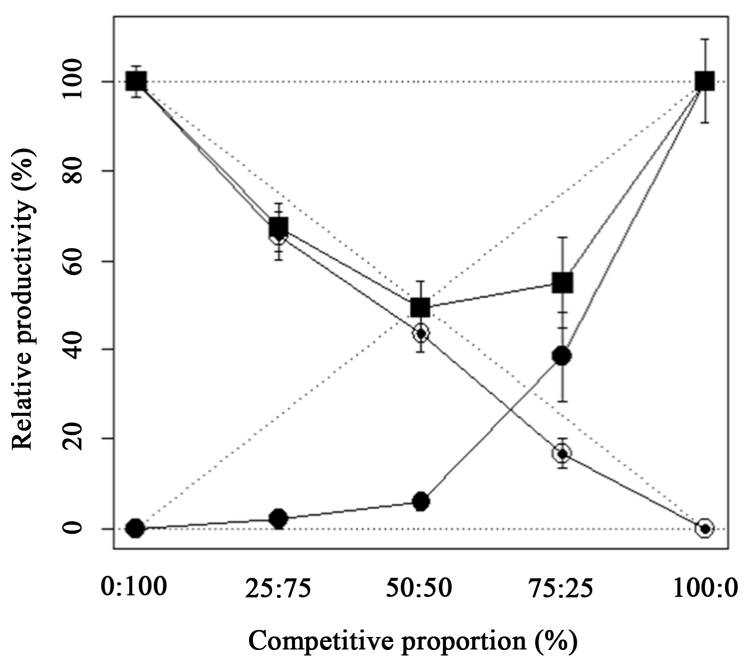

Figure 4. Relative productivity (PR) for shoot dry mass of sourgrass $(\bullet)$ and soybean $(\odot)$, and

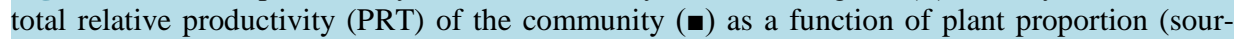
grass: soybean). Dashed lines represent the expected values, in absence of competition, and solid lines the observed values when both species competed in different plant proportions. The standard error bars for treatment replications are presented for each treatment mean. Embrapa Western Agriculture, Dourados-MS, Brazil, 2015.

Table 4. Relative competitiveness (CR), clustering (K) and aggressiveness (A) coefficients for plants of soybean and sourgrass under competition. Embrapa Western Agriculture, Dourados-MS, Brazil, 2015.

\begin{tabular}{|c|c|c|c|c|c|c|}
\hline \multirow{2}{*}{$\begin{array}{l}\text { Species } \\
\text { Soybean }\end{array}$} & \multicolumn{2}{|c|}{ CR } & \multicolumn{2}{|c|}{$\mathbf{K}$} & \multicolumn{2}{|c|}{ A } \\
\hline & $9.971^{*}$ & \pm 0.893 & 0.625 a & \pm 0.002 & $0.364^{*}$ & \pm 0.028 \\
\hline Sourgrass & $0.11^{*}$ & \pm 0.008 & $0.021 \mathrm{~b}$ & \pm 0.009 & & \\
\hline
\end{tabular}

$\mathbf{C R}$ and $\mathbf{A}$ : T-test, being considered significant when differed $(p \leq 0.05)$ from 1 and 0 , respectively. Difference between $\mathbf{K}_{\mathbf{S}}$ and $\mathbf{K}_{\mathbf{s g}}$ were compared by the T-test with Welch criteria, being significant when $p \leq 0.05$.

Corn was affected by the presence of beggartick in all proportions, with reduction between $7 \%$ and $18 \%$ in mass accumulation under competition (Figure 5). Beggartick, however, has been affected in these conditions accumulating only $23 \%$ of the dry mass of the system, compared to the expected $75 \%$ (Figure 5). The greatest losses in the system (PRT) were recorded when beggartick accounted for $75 \%$ of the occupation of the area (75:25), leaving only $25 \%$ of the space available for the crop. Although in minority, the effect of the crop on weed caused about $65 \%$ reduction in total system relative productivity (Figure 5).

Competitiveness (CR), clustering $(\mathrm{K})$ and aggressiveness $(\mathrm{A})$ coefficients indicated that under equivalent levels of competition (50:50) $\mathrm{CR}_{\text {corn }}>1(p=0.024)$ and $\mathrm{A}_{\text {corn }}>0$, indicating advantage for crop, while $\mathrm{K}_{\text {beggartick }}<\mathrm{K}_{\text {corn }}$, indicating relative dominance of the crop on the weed (Table 5).

\subsubsection{Corn versus Sourgrass}

When corn was subjected to competition with sourgrass with simultaneous emergence of plants, the weed was always less efficient than the crop in dry mass accumulation (Figure 6). The average loss of dry mass of corn, at all levels of competition, was of about 7\%, while the weed was strongly inhibited by crop. Even accounting for $75 \%$ of the competitive potential (75:25), the PR of sourgrass was $18 \%$ of the total system, while the expected was $75 \%$ (Figure 6).

Competitiveness (CR), clustering (K) and aggressiveness (A) coefficients indicated advantage for crop, with significant differences for all parameters (Table 6).

Overall, for the four studies by the substitutive (replacement series) method, when corn competes with either beggartick or sourgrass, and also when soybean competed with beggartick, total losses for the system (PRT) were always increasing as the percentage of the weed was increased (Figure 3, Figure 5 and Figure 6); when 


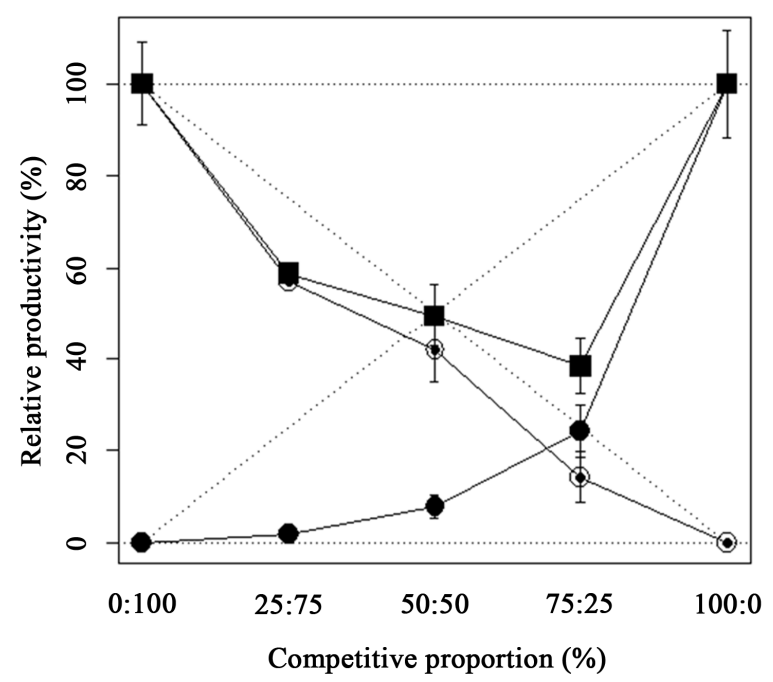

Figure 5. Relative productivity (PR) for shoot dry mass of beggartick $(\bullet)$ and corn $(\odot)$, and total relative productivity (PRT) of the community ( $\mathbf{n})$ as a function of plant proportion (beggartick: corn). Dashed lines represent the expected values, in absence of competition, and solid lines the observed values when both species competed in different plant proportions. The standard error bars for treatment replications are presented for each treatment mean. Embrapa Western Agriculture, Dourados-MS, Brazil, 2015.

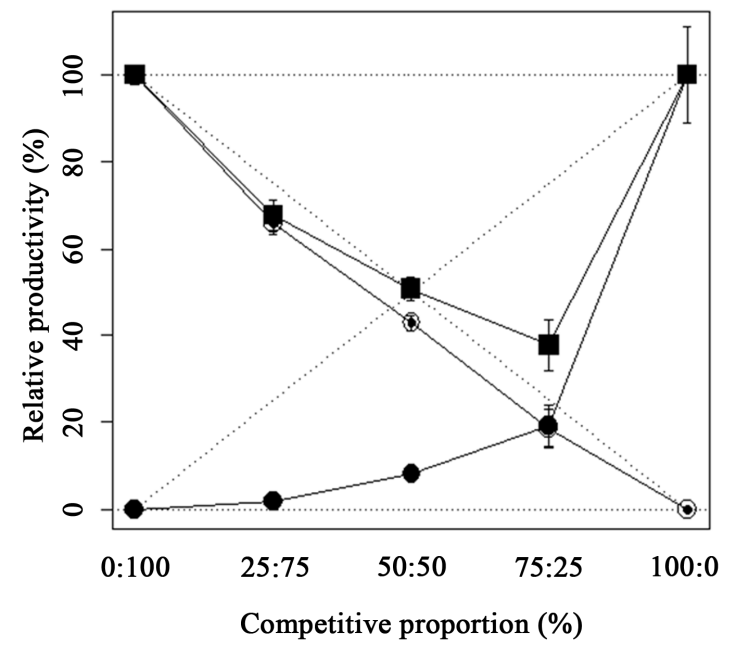

Figure 6. Relative productivity (PR) for shoot dry mass of sourgrass $(\bullet)$ and corn $(\odot)$, and total relative productivity (PRT) of the community (घ) as a function of plant proportion (sourgrass: corn). Dashed lines represent the expected values, in absence of competition, and solid lines the observed values when both species competed in different plant proportions. The standard error bars for treatment replications are presented for each treatment mean. Embrapa Western Agriculture, Dourados-MS, Brazil, 2015.

Table 5. Relative competitiveness (CR), clustering (K) and aggressiveness (A) coefficients for plants of corn and beggartick under competition. Embrapa Western Agriculture, Dourados-MS, Brazil, 2015.

\begin{tabular}{|c|c|c|c|c|c|c|}
\hline \multirow{2}{*}{$\begin{array}{c}\text { Species } \\
\text { Corn }\end{array}$} & \multicolumn{2}{|c|}{ CR } & \multicolumn{2}{|c|}{$\mathbf{K}$} & \multicolumn{2}{|c|}{ A } \\
\hline & $7.347^{*}$ & \pm 0.846 & 3.249 a & \pm 0.034 & $0.738^{*}$ & 0.031 \\
\hline Beggartick & $0.167^{*}$ & \pm 0.023 & $0.028 \mathrm{~b}$ & \pm 0.002 & & \\
\hline
\end{tabular}

CR and A: T-test, being considered significant when differed $(p \leq 0.05)$ from 1 and 0 , respectively. Difference between $\mathbf{K}_{\mathbf{C}}$ and $\mathbf{K}_{\mathbf{B}}$ were compared by the T-test with Welch criteria, being significant when $p \leq 0.05$. 
Table 6. Relative competitiveness (CR), clustering (K) and aggressiveness (A) coefficients for plants of corn and sourgrass under competition. Embrapa Western Agriculture, Dourados-MS, Brazil, 2015.

\begin{tabular}{ccccccc}
\hline Species & \multicolumn{3}{c}{ CR } & \multicolumn{2}{c}{ K } & A \\
\hline Corn & $7.358^{*}$ & \pm 0.357 & $2.295 \mathrm{a}$ & \pm 0.084 & $0.63^{*}$ & \pm 0.086 \\
Sourgrass & $0.14^{*}$ & \pm 0.007 & $0.072 \mathrm{~b}$ & \pm 0.006 & & \\
\hline
\end{tabular}

$\mathbf{C R}$ and A: T-test, being considered significant when differed $(p \leq 0.05)$ from 1 and 0 , respectively. Difference between $\mathbf{K}_{\mathbf{C}}$ and $\mathbf{K}_{\mathbf{S g}}$ were compared by the T-test with Welch criteria, being significant when $p \leq 0.05$.

soybean competed with sourgrass, losses increased with the proportion of the weed to the competitive equivalence (50:50), when they tended to stabilize (Figure 4).

\subsection{Similarities and Differences between Methods}

It should be noted that the competition between plants is more drastic when the involved individuals have similar life cycle, germinate and are included in the same botanical family or have similar morpho-physiological characteristics between themselves. Under these conditions, the great determinant of which species will be most affected is the potential for competition with the species with which it competes. If the emergence of one of the competitors is delayed, usually the individual that germinates first takes advantage in the competition. Thus, one should always install crops in a weed-free area, and ensure its rapid establishment. Of course, if there are differences in the density between crop and weeds, or if crop stand is uneven, weeds may have competitive advantage.

Table 7 presents a summary of results we obtained in the experiments for both methods, where we tried to create a link between them and find the main differences. Although distinct in the interpretation of the data, both competition study methods provided information with practical nature and applicable to the field, though obviously limited because they were basic and exploratory studies. Competition results from controlled environment, regardless of the method of study, must be complemented by field trials.

The substitutive method, when compared to the additive method (Table 7) has two disadvantages: first, it requires the installation of a pre-test to determine the minimum population for each species, from which occurs stabilization in the dry mass. This pre-test, although desirable when choosing the additive method, is not compulsory and density of plants in this study method can be determined per se, at the discretion of an experienced researcher on the subject-since data is interpreted only in the studied range.

The second drawback relates to difficulty in data processing and obtaining the graphics and coefficients inherent to the substitutive method. For the additive method, virtually any statistical software and spreadsheet with basic skills in graphics generation make it possible to analyze experimental data; for the substitutive method, although part of the easiness in installing and conducting the experiment and data collection are similar to the additive method, data analysis software based on programming languages $\left(\mathrm{SAS}^{\circledR}, \mathrm{R}^{\circledR}\right.$ or similar) is demanded. While data processing can be accomplished in spreadsheets also for substitutive experiments, this way is neither easy nor indicated. The script supplied by [10] may turn easier to analyze data from substitutive trials. Research has reported that due to substitutive experiments to be installed in fixed densities, they cannot be used for inferences about mixtures where density is not kept constant [4]. Substitutive experiments are widely used, but the results cannot be easily interpreted because they are so restrictive that valid generalizations should not be made beyond that particular situation inherent in the experiment. The findings of most studies using this method require some review [4].

When comparing the results obtained by both methods of study (Table 7), no profound limitations to the substitutive method were found to the point of not allowing its use or to put in check its results, as reported in some studies [4]. We agree, however, that in finalistic studies under field conditions or in situations where it needs more directly applicable inferences, the additive method should primarily be adopted.

If from one side there are disadvantages, from the other side the substitute method has the advantage of obtaining information as to the community as a whole, providing evidence about the nature of competition between species involved - if it occurs for the same resources, or if one of the species is able to avoid the competition. In addition, discrete varietal differences in competitive ability against weeds are probably best captured by substitutive experiments. 
Table 7. Comparison between additive and substitutive experimental methods of studying competition between soybean and corn against the weed species beggartick and sourgrass. Embrapa Western Agriculture, Dourados-MS, Brazil, 2015.

\begin{tabular}{|c|c|}
\hline Notes from the Additive Method & Notes from the Substitutive Method \\
\hline $\begin{array}{l}\text { Beggartick reduces dry mass } \\
\text { accumulation in soybean, even at low densities }\end{array}$ & $\begin{array}{l}\text { Beggartick reduces slightly soybean dry mass, in any proportion, } \\
\text { when plant density in the system is near the maximum }\end{array}$ \\
\hline $\begin{array}{l}\text { More than } 20 \text { beggartick plants } \cdot \mathrm{m}^{-2} \text { are } \\
\text { highly impacting on soybean grain yields }\end{array}$ & Even in minority, beggartick is highly capable of reducing crop yields \\
\hline $\begin{array}{l}\text { Beggartick reduces linearly dry mass } \\
\text { accumulation in corn as infestation increases }\end{array}$ & $\begin{array}{l}\text { Corn is affected by beggartick in constant ways, } \\
\text { independently of density of the weed }\end{array}$ \\
\hline $\begin{array}{l}\text { Sourgrass is not capable of impact soybean significantly, } \\
\text { when under equivalent densities and under } \\
\text { concomitant emergence (plants originated from seeds) }\end{array}$ & $\begin{array}{l}\text { Soybean is highly capable of competing against sourgrass, } \\
\text { even when the weed is superior in density; there are, } \\
\text { however, losses in dry mass accumulation by the crop }\end{array}$ \\
\hline \multirow[t]{2}{*}{$\begin{array}{l}\text { The reduction in dry mass accumulation of corn } \\
\text { was linear to the increase in sourgrass density }\end{array}$} & $\begin{array}{l}\text { Corn potential to compete against sourgrass is constant, } \\
\text { with minor losses by competition }\end{array}$ \\
\hline & $\begin{array}{l}\text { For all situations, there is mutual prejudice in growth } \\
\text { for all species under competition, at different levels (PRT < 100) }\end{array}$ \\
\hline
\end{tabular}

\section{Conclusions}

Crops were more competitive than weeds used to compare experimental methods, because weeds were not adapted to be as responsive to availability of environmental resources as crops.

According to the hypotheses, the distinct methods of study showed similar results in some ways, but with different approaches and conclusions. Depending on the situation, either method should be preferred.

It was found that the additive method of study provided more practical results, more similar to field conditions, where the greatest losses were not caused by individual competition, but by the community. This method must be used when one wants to assess the effects and quantify the influence of the density of the weed community on crops aiming to subsidize decision-making for weed control in commercial fields.

The substitutive (replacement series) method, on the other side, should be used to evaluate competition between weeds and crop plants when scientific comprehension about the competitive process is needed, especially when related to study the best competitor. These results are the most suited for in-depth studies on the morphological and physiological characteristics, as it provides information and coefficients that describe in detail the behavior of the species under study, in its competition for environmental resources.

\section{Acknowledgements}

Authors would like to thank Embrapa, CNPq and FAPERGS for the financial grants which made this study viable.

\section{References}

[1] Burkholder, P.R. (1952) Cooperation and Conflict among Primitive Organisms. American Scientist, 40, 601-631.

[2] Silva, A.A. and Silva, J.F. (2007) Tópicos em manejo de plantas daninhas. Universidade Federal de Viçosa, Viçosa.

[3] Barbour, M.G., Burk, J.H., Pitts, W.D., Gillian, F.S. and Schwartz, M.W. (1998) Terrestrial Plant Ecology. Benjamin/ Cummings, Menlo Park.

[4] Silvertown, J. (1987) Introduction to Plant Population Ecology. 2nd Edition, Longman Group United Kingdom, Essex.

[5] Radosevich, S., Holt, J. and Ghersa, C. (2007) Ecology of Weeds and Invasive Plants: Relationship to Agriculture and Natural Resource Management. Wiley, New York. http://dx.doi.org/10.1002/9780470168943

[6] R Development Core Team (2012) R: A Language and Environment for Statistical Computing. R Foundation for Statistical Computing, Vienna. http://www.R-project.org 
[7] Cumming, G., Fidler, F. and Vaux, D.L. (2007) Error Bars in Experimental Biology. The Journal of Cell Biology, 177, 7-11. http://dx.doi.org/10.1083/jcb.200611141

[8] Agostinetto, D., Galon, L., Moraes, P.V.D., Rigoli, R.P., Tironi, S.P. and Panozzo, L.E. (2008) Competitividade relativa entre cultivares de arroz irrigado e biótipo de capim-arroz (Echinochloa spp.). Planta Daninha, 26, 757-766. http://dx.doi.org/10.1590/S0100-83582008000400007

[9] Santos, J.B. and Cury, J.P. (2011) Picão-preto: uma planta daninha especial em solos tropicais. Planta Daninha, 29, 1159-1172. http://dx.doi.org/10.1590/S0100-83582011000500024

[10] Concenço, G. and Galon, L. (2014) Script para análise de experimentos de competição pelo método substitutivo no "R”. Embrapa Western Agriculture, Dourados.

http://ainfo.cnptia.embrapa.br/digital/bitstream/item/114713/1/DOC2014124-com-Anexos.pdf 